\title{
Teaching and Learning with Clickers: Are Clickers Good for Students?
}

\section{Emma D. Bojinova, Department of Economics \& Finance, and James N. Oigara, Department of Education, Canisius College, Buffalo, NY, USA}

Note: both authors contributed equally to this work

\section{bojinove@canisius.edu; oigaraj@canisius.edu}

\begin{abstract}
Student response systems (clickers) are becoming very popular in classroom instruction. The majority of the published papers investigate how students feel about clickers. There is limited research regarding clickers' influence on student learning. The purpose of this study is not only to evaluate students' experiences and perceptions about the use of clickers, but also to find out whether they have a positive impact on student learning. Data from student surveys supplemented by exam grades were used to analyze these goals. Students in two undergraduate courses in the spring of 2011 utilized clickers for review and practice question sessions. Overall, students gave high approval ratings for this technology, particularly in increasing their participation and engagement in lectures. We found no significant difference in the class mean final examination scores for students taught with clickers (treatment group) compared to those taught in a traditional class setting (control group). However, the range of final exam scores and final course grades were smaller for the class with clickers compared to the class without clickers. The treatment group had also smaller variances in terms of both final exam scores and final grades which suggest that the spread of their scores was much closer to the mean compared to the class without the clickers. Based on the findings from survey responses, interviews, and analysis of final grades we found that the use of clickers appears to increase student engagement and achievement compared to traditional lecture format instruction. The implications for using clickers to improve active teaching and learning are discussed.
\end{abstract}

Keywords: Clickers, SMART response system, student response systems, interactive technology, student engagement, active learning

\section{Introduction}

Technologies have been coming in and out of our culture, and today one of the most groundbreaking advancements in education is interactive technology. The Clicker system is used in hun-

Material published as part of this publication, either on-line or in print, is copyrighted by the Informing Science Institute. Permission to make digital or paper copy of part or all of these works for personal or classroom use is granted without fee provided that the copies are not made or distributed for profit or commercial advantage AND that copies 1) bear this notice in full and 2) give the full citation on the first page. It is permissible to abstract these works so long as credit is given. To copy in all other cases or to republish or to post on a server or to redistribute to lists requires specific permission and payment of a fee. Contact Publisher@InformingScience.org to request redistribution permission. dreds of college classes around the United States. Clickers, also known as

Personal Response Systems (PRS), Student Response Systems (SRS), and Automated Response Systems (ARS), represent some of the powerful interactive technologies in the classroom that can be used to promote active learning. A clicker is a little device that lets an instructor take a real-time poll of the class. Each clicker has a number of but- 
tons (e.g., labeled A through E) corresponding to answer choices to a question posed by the instructor. A real-time histogram is created showing the class responses. This enables the instructor to get a snapshot of whether the class is following his or her lecture content, both by seeing the histogram and by hearing conversations that students have with each other.

The price for the clicker system varies depending on the type purchased. The cost of a clicker device sold in the United States ranges between \$20-60 on average. Students also need to pay an activation fee each semester they use it in class (\$15-25). In addition, the institution has to buy software from a distributing company. The clicker system that we used in our study is SMART Response PE model. Classroom packages range between $\$ 1,000$ for a set of 12 to $\$ 3,000$ for a set of 48 clickers. This is a one-time cost of clicker devices, receiver, and the SMART Response software. For this clicker model students do not have to pay an activation fee once the SMART Response software has been purchased by the institution or the instructor. The clickers can be used in multiple courses. They are not assigned to only one student but all students with or without their unique identification number can use each device.

If students do not feel involved in the learning process, they are less likely to work hard to make sense of the presented material and, therefore, less likely to perform well on assessments measuring their learning. Research in educational technology shows that the use of clickers improves classroom interactive atmosphere (see for example Draper, Cargill, \& Cutts, 2002; Laurillard, 1993). When used correctly, this technology can result in a remarkable transformation of a classroom, leading to better learning outcomes and enjoyment in a given course through increased interaction and engagement of students with their instructor and peers. With clickers, students have an input device that lets them express their views and understanding of the content. Each clicker device can be numbered or coded by the instructor for tracking student responses and recordkeeping after each class session. This enables the instructor to gauge student understanding and respond accordingly. In a lecture environment students may be unwilling to volunteer information regarding their level of understanding of the covered material. A student who is unsure of the correct answer may be unwilling to take the risk of being incorrect. As a result only one or two students have the opportunity to answer a question. Even if the answer to the question is correct, the instructor has no way to gauge if all other students knew the correct answer. Clickers can be used as a means of anonymously testing students' understanding of the subject matter. During the question-and-answer session, the instructor allows the students to discuss their responses with their peers before showing them the correct answer. This process provides an opportunity for collaboration, active learning, peer instruction, and interaction. It also allows students to understand which answers they got wrong or right and why. In short, clickers help the instructor to obtain instant feedback on how well students are following the material presented in class, potentially promoting not just student engagement but also performance.

Personal Response Systems are rapidly gaining popularity among instructors from all over the world. Literature shows that clickers have been primarily used in Psychology, Philosophy, Biology, Computing Science, Sociology, Statistics, Nursing, Physics, and Education classes (see for instance Dolinsky, 2001; Maletiou-Mavrotheris, 2003; Maletiou-Mavrotheris, Paparistodemou, \& Stylianou, 2009; Morling, McAuliffe, Cohen,\& DiLorenzo, 2008; Pan \& Tang, 2004; Stowell \& Nelson, 2007). Majerich, Stull, Varnum, and Ducette (2011) found that integrating clickers into the physics course with multiple-choice questions and having in-class discussion of results had positive effect on students' achievement. On average, students who used clickers achieved significantly higher scores on their examinations compared to the group that did not utilize clickers. In another study, Stagg and Lane (2010) found that the use of clickers provided an effective and efficient means to actively engage and facilitate student learning in an information literacy class. The surveyed students reported also that clickers were easy and fun to use. K. Johnson and Lillis (2010) indicated that the use of audience response system in a microbiology module improved 
student motivation and attention and provided immediate feedback to the instructor concerning student understanding of the content. Students said that clickers helped them stay focused, verify their understanding, and learn the material more effectively.

There has been limited research in Economics or Geography classes. In addition, the majority of the studies have focused on students perceptions regarding the use of clickers, and there has been insufficient research regarding their value, effectiveness, and impact on instruction. Also the research has not considered the effects of using clickers in conjunction with other engaging instructional methods. More empirical studies are needed to examine the effectiveness of using technological innovations such as clickers in enhancing student learning.

The goals of this study are to survey students on their perceptions regarding the use of clickers in classroom instruction compared to traditional lecture methods and to examine the extent to which clickers influence student engagement and performance in a Physical Geography and Principles of Microeconomics undergraduate classes. The main contribution of this research is the comparison between the learning outcomes in two sections of the same course taught by the same instructor by designing an experiment based on treatment and control groups and also testing for the significance of the results. This paper also highlights the best ways of using clickers to facilitate peer discussions, develop critical thinking among students, and enhance deeper learning.

\section{Previous Literature}

Research in the field of educational psychology has shown that engaging students in active learning is a more effective teaching strategy than traditional teacher-centered pedagogical styles (Glaser, 1990; Jonassen, 1995). For the purpose of this study, active learning simply means that students become cognitively engaged with the information presented; they select, organize, and integrate new information into their existing knowledge structures, rather than just passively listening to someone else's version of the way things are (Mayer, 2002). Based on a social constructivist view of learning, this study assumes that knowledge construction and understanding is significantly enhanced through human interaction (Brown, Collins, \& Duguid, 1989; Driscoll, 2005; Lave \& Wenger, 1991; Vygotsky, 1978). In the classroom, this type of interaction includes both instructor-learner and learner-learner communication and collaboration.

Recently clickers have received considerable attention in the educational technology literature, and their use in college classrooms has increased dramatically (MacGeorge et al., 2007). Some research studies have shown that clickers are useful tools for engaging students in active learning during lectures, enhancing students' overall communication, and helping instructors create a more learner-centered classroom (Beatty, 2004; Caldwell, 2007; Draper \& Brown, 2004; MacGeorge et al., 2007).

Fies and Marshall (2006) conducted a review of 24 selected publications concerned with student response systems and their instructional use. The authors found that the most commonly-stated student benefits of clickers were improved attendance and participation, as well as enhanced perceptions of classroom interactivity (i.e., students felt the class was more interactive, more engaging, and more enjoyable). Moreover, a number of researchers indicated that clickers helped students and instructors become more aware of students' understanding, which ultimately improved instruction.

In another study Caldwell (2007) examined the literature on applications and classroom outcomes of clickers use in large-enrollment classes. Caldwell found that clickers have successfully been used primarily to (a) increase classroom interactivity, (b) assess student preparation, (c) find out more about students understanding of concepts, (d) conduct formative assessments, and (e) review class materials and practice questions. 
According to Wit (2003) students in general have a positive attitude towards clickers. He found that $74 \%$ of the students that used clickers thought that they "had been very useful in aiding their understanding of statistics" (p. 19). Kyei-Blankson (2009) surveyed twenty students in her statistics class regarding their perceptions of clicker use in class. Survey results revealed that the majority of students (78\%) thought that clickers were an appropriate teaching tool, $78 \%$ said that they appreciated the anonymity of the process, about $83 \%$ indicated that the feedback from review sessions with clickers helped them monitor their understanding of the subject matter, and about $83 \%$ of the students said that they were in general comfortable using this technology. In addition, $72 \%$ of the students liked that clickers showed them what their peers were thinking and also many of them (61\%) indicated that clickers promoted an effective learning class experience. The author also used treatment and control groups to evaluate if there were differences present in the mean final exam test scores between these two groups. An independent t-test analysis showed that "the range of scores of students in the clicker class was slightly smaller than the range of scores for students in the control group". Buhay, Best, \& McGuire (2010) studied whether library instruction would be more effective with the use of clickers but more importantly they provided evidence that even if some students in a class do not have clickers they still benefit from participating in review sessions.

Overall, the use of clickers was found to increase classroom interactivity (learner-learner and learner-instructor interaction) and engagement in class activities, to improve student understanding and learning, to improve achievement on exams, to increase attendance, to provide real-time feedback to instructors about student misconceptions, and to promote a more positive, active, and fun atmosphere in the large classroom (see Caldwell, 2007).

\section{Using Clickers for Active Learning}

The benefits of active learning are widely discussed in the literature. Guthrie and Carlin (2004) state that the twenty first century students are primarily active learners and the traditional lecture method has increasingly become out of touch with how students engage in their world. The benefits of clickers in the classroom according to J. T. Johnson (2005) can be summarized as follows. First, this technology actively encourages students to participate in class and express their understanding of the presented material due to the anonymity of the system. It helps students overcome the fear of providing a wrong answer and as a result to be ridiculed by the instructor or their fellow students (i.e., promotes participation without any intimidation). Second, clickers encourage student discussion of the material covered in class. This can be achieved in two ways: students can discuss the possible answers on multiple-choice questions with their neighbors and then they can choose the answer that they consider correct, or alternatively students can be asked to select an answer according to their understanding of the material and after they are shown the distribution of the results and have a short discussion with their peers they are given a second chance to answer the same question. Third, clickers provide prompt and valuable feedback to students and the instructor about the class general level of understanding of the content material covered during the question-and-answer sessions. Therefore, this technology can be used as a tool of formative assessment and can help instructors evaluate the difficulties that students have with a particular topic. Fourth, clickers are fun to use as the generation of current students loves technology. Clickers follow the principles of game-based learning. The twenty-first century students have grown up using computer games. Short sessions with the use of clickers make class time more enjoyable by breaking up the monotony of the lecture. 


\section{Methodology}

\section{Clickers Overview}

This study used SMART Response Systems PE model. The system works with or without a classroom SMART Board. The handheld devices look similar to a TV remote control or over-sized cell phone. Students select an answer on the device, it is collected by a radio frequency receiver, and a computer logs the answers of each individual student for the teacher to review instantly with the class or later in private. Quizzes are created using the SMART Notebook software.

Instructors have the ability to poll the class on their understanding of concepts by asking true or false questions, numerical answer questions, multiple choice or multiple answer questions, text and yes or no questions. Teacher analysis tools are included to manage assessment results and help plan future student instruction. The ability to print and prepare student reports is also available with this model. The instructor can ask questions orally, write them on the board, or assign a question from a textbook, and students can reply safely knowing that their peers do not see their answers. Once students have responded, the instructor can view the class results as a pie chart or as a bar graph. The results can be viewed by the whole class on a projector screen or SMART board, or in private on the instructor's computer. The instructor has also access to the individual record of each and every student's answer in the Teacher Tools section of Notebook which helps to monitor class progress and understanding.

\section{Participants}

The study participants were the undergraduate students enrolled in ECO 102: Principles of Microeconomics and GEO 325: Physical Geography in the spring of 2011 semester at a 4-year private college in the United States. There were two sections of ECO 102 - one of them used clickers (treatment group) and the other one did not have practice sessions with clickers (control group). The number of students in the control group was much smaller (21 students) than the experimental group ( 40 students). The treatment group was chosen for its larger size but the researchers did not have beforehand knowledge about the quality of the students in the two sections of this course. The selection was based on the assumption that a larger class is much more difficult to get involved in active discussions and students are less likely to communicate openly with the instructor, and, therefore, clickers might be more beneficial in such a setting as shown by previous studies.

The demographic data in Table 1 shows that the students in the two classes that used clickers (Eco 102 treatment group and Geo 325) have similar characteristics. The median age of the participants in both classes was the same, 19 years. The average age was also very similar (see Table 1). There were slightly more male students in the Microeconomics class compared to the Geography class ( $48 \%$ versus $45 \%$ ). The average cumulative GPA for the prior semester of the students in the Geography class was slightly higher than the mean GPA of the Microeconomics class. Almost the same percentage of the participants in each class reported to be living on campus $(61.3 \%$ in Eco 102 and 60\% in Geo 325). Over 64\% of the students indicated to be freshmen. More than $90 \%$ of the respondents stated that their primary residence is New York state. 
Table 1: Student Demographic Characteristics

\begin{tabular}{|l|rrr|}
\hline & Eco 102 (Treatment Group) & Eco 102 (Control Group) & Geo 325 \\
\hline Mean Age & 19.2 & 21.9 & 20.9 \\
Min Age & 18 & 18 & 18 \\
Max Age & 26 & 51 & 40 \\
Median Age & 19 & 19 & 19 \\
Students over 39 years old & 0 & 1 & 1 \\
\% Male & 48.4 & 45.5 & 45.0 \\
Mean cumulative GPA & 2.9 & 3.0 & 3.1 \\
\% Live on Campus & 61.3 & 27.3 & 60.0 \\
\% Freshman & 77.4 & 54.5 & 65.0 \\
\% Residing in NY State & 90.3 & 90.9 & 95.0 \\
Number of Students in Class & 40 & 21 & 24 \\
Number of Survey Respondents & 31 & 11 & 20 \\
\hline
\end{tabular}

The two Microeconomics classes (control and treatment groups) also look very similar - the minimum age, the median age, and the percentage of students residing in the state of New York were the same. There were a little bit more male students in the class with clickers. There were more freshman in the treatment group than in the control group (77.4\% versus $54.5 \%)$ and more of the students in the former class reported to live on campus than in the latter class $(61.3 \%$ compared to $27.3 \%$ ). The mean cumulative GPA as of the prior semester of the non-clicker class was also slightly higher than the clicker class. One student in the control group was over 39 years old which makes the age distribution of this class slightly more skewed to the right as compared to the treatment group. As a result, the performance of the non-clicker class can be influenced by this outlier having in mind that older students tend to be more knowledgeable and have more experience than a typical student (a student at the $50^{\text {th }}$ percentile).

\section{Procedure}

The study was approved by the College Internal Review Board. Students received a consent form, which provided all details regarding the research project. If a student was not willing to participate in this research, they were given the opportunity to decline on the consent form. Participants were also given the opportunity to withdraw their consent and to discontinue participation at any time without penalty.

The project started with an introduction of the SMART Response System (clickers) in the abovementioned classes during the spring semester of 2011. The students learned how to use clickers during class time to answer questions raised by the instructors. They were given a clicker to use in class during review or practice sessions and quizzes. Students did not have to buy a clicker device themselves and this removed the financial obligation of having one which can have some impact on how participants feel about clickers.

During the first week of class, every student was given a unique identification number to use with a clicker transmitter throughout the semester, and this identification number was registered to the student in each instructor's computer-based database. During each clicker-based session, students were handed clickers to use and they returned them at the end of class. Clickers helped to bring about student involvement through peer discussion. The instructors used clickers to survey students' answers to thought-provoking content questions. During a clicker-facilitated lecture, the following activities occurred: (a) the instructor presented questions on the projector screen; (b) students worked in groups to reach an answer, (c) students voted either individually or in groups, (d) a pie chart of the results was displayed. Then, two approaches were used. With the first approach, known in the literature as the Dufresne sequence (see Dufresne, Gerace, Leonard, Mestre, $\&$ Wenk, 1996), the pie chart revealed the correct answer and a class-wide discussion followed. 
With the second approach (Mazur sequence), the pie chart did not show the correct answer, only the distribution of student responses; a peer discussion followed, and then students voted again (Mazur,1997). Afterwards, students were given the correct answer, and again a class-wide discussion was initiated to explain the correct answer. In many cases after the second voting there was a significant improvement in class performance based on the selection of the correct answer.

In this study data was collected in the form of clicker quizzes, end of semester student surveys to evaluate student attitudes regarding the use of clickers, student interviews in the Geography class, and exam grades in the two sections of the Microeconomics class to analyze student overall performance.

In the Microeconomics class, students used clickers for practice questions for almost each chapter of the covered material ( 7 times during the semester). The majority of the sessions were based on a class-wide discussion (a simplified version of the Dufresne sequence). Students were randomly given a clicker (not everybody in the class had one). They were asked to discuss each question with their neighbors before selecting an answer. The time allocated for answering a question was either one minute or one minute and thirty seconds. Two of the practice sessions followed a version of the Mazur sequence of peer instruction. Students voted for an answer to a question and the instructor showed the distribution of responses to the class without telling the correct answer. Then students were given a second chance to answer the same question after a short discussion with their peers. They had to convince their fellow students that their answer was correct. For the practice sessions the participants did not get any points but instead clickers were used to facilitate discussions and provide feedback to both the students and the instructor about general understanding of the economic concepts.

In the Geography class, clickers were used weekly for concept quizzes (about 12 times during the semester). The quizzes consisted of approximately five questions, with a multiple choice, multiple answer, numerical, or true/false question that covered the lecture content. The instructor administered 3 exams, which contained 50 multiple-choice questions and thirty percent (15 questions) of each exam covered similar questions to the clicker material, although the verbatim of the clicker questions was altered.

In each lecture, during or after a section of the lecture, the instructor presented a sample of multiple-choice or true/false questions on the screen using SMART Notebook presentation software. The instructor introduced the question by saying something like, "OK, now let us see how well you understood the material we just covered or read about. Please take out your clickers and press $\mathrm{a}, \mathrm{b}, \mathrm{c}$, or d." When all students had pressed a button on their response transmitters (which generally took 20 to 30 seconds), the instructor displayed a pie chart showing the correct answer and the percentage of students who selected each answer. Then, a short discussion started concerning the rationale for the correct answer, which the instructor summarized afterwards. The instructor initiated the discussion by asking a question such as, "Why is c the correct answer?" Approximately 2 minutes of class time was used for each question. The SMART response software recorded each student's response and allocated 1 point for each correct answer. Students could earn up to 40 points in course credit for answering the "clicker questions" in class and could check their points on the class website.

\section{Results}

\section{Survey Results}

Toward the end of the semester, students were asked to voluntarily participate in a survey to evaluate the usefulness of SMART Response System as an instructional tool. The questionnaire collected basic demographic information and self-reported course-related activities. It contained var- 
ious questions aimed at analyzing students' perceptions about clickers by asking them to report on their satisfaction with clickers, the degree to which clickers increased their interest in learning the course content, their perception of the clicker increasing their cognitive effort in the class, the ability of the clicker to boost their understanding of the material, and their raised motivation as a result of using this technology in the course. The majority of these questions were Likert-scale type ranging from "strongly agree" to "strongly disagree" statements but there were also openended; there were also some general demographic questions.

Overall, students from both classes had a positive attitude towards the use of clickers as an instructional tool. Survey participants said that clickers were easy to use and helped them understand the subject matter compared to traditional lecture-based classes (see Table 2 for details). Almost all (93.55\% in the Economic class and 100\% in the Geography class) felt that they were more engaged in the class material because clickers were used. Students in both courses thought that using clickers was fun and made the class more enjoyable $(90 \%$ in the Eco 102 and $80 \%$ in Geo 325). They reported that clickers increased their concentration in the class $(80.65 \%$ in the Microeconomics class and 70\% in the Geography class) and made them more aware of their misunderstandings about the course material (90.32\% and 80\% in Eco 102 and Geo 325, respectively).

Table 2: Student Survey Responses by Course (Data in \%)

\begin{tabular}{|c|c|c|c|c|c|c|}
\hline & \multicolumn{3}{|c|}{ Eco 102} & \multicolumn{3}{|c|}{ Geo 325} \\
\hline & Strongly & & Disagree & Strongly & & Disagree or \\
\hline & Agree \& & & or Strongly & Agree \& & & Strongly \\
\hline & Agree & Neutral & Disagree & Agree & Neutral & Disagree \\
\hline Clickers are easy to use & 100.00 & 0.00 & 0.00 & 100.00 & 0.00 & 0.00 \\
\hline Clickers made the material less interesting & 16.13 & 6.45 & 77.42 & 5.00 & 0.00 & 95.00 \\
\hline I felt more engaged in the class material & 93.55 & 6.45 & 0.00 & 100.00 & 0.00 & 0.00 \\
\hline $\begin{array}{l}\text { Clickers helped me understand the subject matter } \\
\text { compared to traditional lectures }\end{array}$ & 77.42 & 22.58 & 0.00 & 65.00 & 35.00 & 0.00 \\
\hline Clickers increased my concentration in this class & 80.65 & 19.35 & 0.00 & 70.00 & 30.00 & 0.00 \\
\hline $\begin{array}{l}\text { Clickers inspired me to study more compared to } \\
\text { traditional classes }\end{array}$ & 25.81 & 58.06 & 16.13 & 45.00 & 35.00 & 20.00 \\
\hline I appreciate the anonymity of the clicker process & 80.65 & 16.13 & 3.22 & 70.00 & 30.00 & 0.00 \\
\hline $\begin{array}{l}\text { I am more likely to participate in class with clickers } \\
\text { compared to hand-raising }\end{array}$ & 93.55 & 6.45 & 0.00 & 95.00 & 5.00 & 0.00 \\
\hline $\begin{array}{l}\text { Immediate feedback from instructor helped me to } \\
\text { understand the concents }\end{array}$ & 100.00 & 0.00 & 0.00 & 100.00 & 0.00 & 0.00 \\
\hline Clickers make me more aware of my & & & & & & \\
\hline misunderstandings compared to traditional classes & 90.32 & 9.68 & 0.00 & 80.00 & 20.00 & 0.00 \\
\hline $\begin{array}{l}\text { Discussions with peers helps me to understand } \\
\text { better the course material }\end{array}$ & 74.20 & 19.35 & 6.45 & 80.00 & 20.00 & 0.00 \\
\hline $\begin{array}{l}\text { Distribution of class responses helps to increase my } \\
\text { confidence }\end{array}$ & 67.7 & 32.2 & 0.00 & 80.00 & 15.00 & 5.00 \\
\hline I would recommend using clickers in this course & 96.67 & 3.33 & 0.00 & 85.00 & 15.00 & 0.00 \\
\hline Using clickers improved my grade in the course & 38.71 & 61.29 & 0.00 & 60.00 & 35.00 & 5.00 \\
\hline $\begin{array}{l}\text { Clickers make the class more enjoyable compared } \\
\text { to traditional classes }\end{array}$ & 90.00 & 10.00 & 0.00 & 80.00 & 20.00 & 0.00 \\
\hline Overall I am satisfied with the use of clickers & 100.00 & 0.00 & 0.00 & 90.00 & 10.00 & 0.00 \\
\hline
\end{tabular}

More than $93 \%$ of the students stated that they were more likely to participate in a class with clickers compared to traditional hand-raising. They also said that they appreciate the anonymity of the clicker process $(80.65 \%$ in Eco 102 and 70\% in Geo 325). All students agreed that the immediate feedback from the instructor helped them understand the concepts better. Discussions of the clicker questions with their peers were also beneficial for student understanding of the course material. At least two-thirds of the participants thought that the distribution of class responses 
shown in a pie chart after answering a question helped them increase their confidence in how well they knew the subject.

It was disappointing to find out that not many students were inspired to study more because clickers were used compared to the traditional lecture-style classes. We should note though that there are many other things that also influence student learning (e.g., intelligence, time, motivation, and learning styles). It was surprising that only $39 \%$ of the Microecomics students stated that the use of clickers improved their grade in the class and all the others were neutral with respect to this question. However, $60 \%$ of the Geography students felt that clickers increased their performance in the course. A possible explanation for this can be that Eco 102 students were not given any points for participation in the practice sessions with clickers whereas Geo 325 students received some credit for these sessions.

None of the participants felt that clickers were a waste of time but instead they were satisfied on how they were used in both courses. In particular, all of the Economics students and $90 \%$ of the Geography students agreed or strongly agreed to this statement. The majority of the survey participants would also recommend the use of clickers in future classes.

\section{Interview Results}

At the end of the semester the geography course instructor conducted one-on-one interviews with four volunteer participants ( $20 \%$ of the survey respondents) to evaluate in more detail the value of clicker technology in the student learning process. Based on qualitative comments, several themes emerged repeatedly including increased engagement, participation and student attention, ability to see what classmates knew, benefit of the immediate feedback, anonymity of clickers, and a fun teaching method.

The most common theme was that the use of clickers promoted both individual and group participation about the subject material during class. The importance of students being active and taking more responsibility for their learning also emerged in students' responses to the open-ended question at the end of the semester written surveys. Participants felt that they participated more in class when clickers were used. Below are some of the respondents' quotations to this theme.

"It forced you to be more active, rather than just copying something down from the notes and not thinking about it."

"I liked that the instructor would... have us talk to our neighbor, figure the question out, and then by the end of class, you had pretty much understood everything."

Students reported having fun using clickers and also appreciated them as an educational tool for instruction. Participants reported that they liked being able to check their knowledge and comprehension of the class material, without being graded. All interviewees liked clickers because they allowed them to participate in class while remaining anonymous. This was also a common theme on the surveys. Below are some quotations from the interviewees.

"It was anonymous so you didn't feel bad if you got the question wrong."

"It's not like you're raising your hand, so you don't feel stupid for wrong answer."

"... The instructor would start out the new subject material..., by asking us questions like what we knew about it, and that's kind of cool because we were able to see what we knew and what we didn't know about the material. Then the instructor will work out something clearly and valuable to help us learn about it."

"I liked the questions in the middle and end of the lecture because I felt that it sort of tested whether or not I understood what we just went over in class." 
Interviewee respondents recognized that the instructor not only used the clickers to promote class discussion but also to make immediate adjustments in teaching that benefited the class. Below are quotations from the interviewee that supports this statement.

"I liked when we did the questions twice for when you were confused, you would discuss with a partner and go back and answer it again ..."

"If $99 \%$ of the class chose the right answer, we could just move on. However, lower than that we had a class discussion that helped to clear up things for those confused."

Another common theme that emerged was the usefulness of clicker questions to break up a lecture and to refocus the students' attention. Below is a quote that supports this theme.

“...Whenever during the lecture the instructor is like 'Answer the question.' you knew, you had to pick up the clicker and answer."....."If you were not paying attention it was a way to come back and get involved again."

\section{Treatment and Control Group Results}

The two sections of the Principles of Microeconomics classes served as treatment and control groups as mentioned before. Our goal was to see whether clickers improved the grades of the students in the treatment group (i.e. the group that used clickers for practice sessions). Both sections had review sessions for almost each chapter that was covered in class but the difference was that the section that used clickers had the chance to answer the questions anonymously and was much more involved in peer discussions, whereas the other section had the same practice questions but they were answered and discussed in a more traditional class setting.

Table 3: Mean Exam Grades for the Treatment and Control Groups (Unadjusted Scores)

\begin{tabular}{|l|rr|}
\hline & Eco 102 (Clicker secton) & Eco 102 (Non-clicker section) \\
\hline Exam 1 & $73.34 \%$ & $76.81 \%$ \\
Exam 2 & $72.35 \%$ & $72.13 \%$ \\
Final Exam & $67.45 \%$ & $72.21 \%$ \\
\hline
\end{tabular}

Table 3 provides the mean exam grades of the two classes. The grade items that made up the final grade score (maximum of 450 points) were as follows: online homework assignments $(20 \%$ of final grade), in-class or take-home quizzes $(8.9 \%)$, two midterm exams $(22.2 \%$ each), and a final exam $(26.7 \%$ of final grade). The second midterm exam and the final exam grades were curved the same way for both the treatment and control groups (a flat increase for everybody - e.g., 5 pts added to students' exam scores). No other adjustments were made to the grade score and the same grading procedure was applied to both classes.

It is interesting to see that initially the control group performed better than the treatment group. In particular, the average grade on the first exam of the section without clickers was $3.47 \%$ higher than the mean grade of the "clicker" section. However, the results for the second midterm exam were reversed. The treatment group performed slightly better which was in accordance with our expectations. This suggests that over time sessions with clickers might be beneficial to students. To our surprise, the final exam grades indicated that once again the mean of the control group exceeded the mean grade of the treatment group. A possible explanation for this might be that the control group might have been better to start with as supported by the mean cumulative GPA (see Table 1). The final exam in this class was comprehensive (cumulative) and the use of clickers was rather limited, just 2 practice sessions in between the second midterm exam and the final exam, which might have influenced the performance of the two sections. It should be noted that the "clicker" class was larger - 40 students versus 21 in the "non-clicker" class. None of the students withdrew from this class whereas 2 students from the "non-clicker" class, due to their bad per- 
formance, decided to drop the class about two weeks prior to the end of the semester. This might have helped the control group to regain their higher scores. It should be also mentioned that the control group had one returning student (over the age of 40 with greater work experience) and that this student performed well in the class. His exam grades on average were above the mean and the median grade - the highest in the class for exam 1 and in the B range for the second midterm and the final exam.

We performed a t-test to check whether the mean final exam scores of the two classes were statistically different at the $5 \%$ level. The null hypothesis is that the means are the same (the mean difference is zero) and the alternative hypothesis is that they are not equal. The results indicate that the mean difference is not statistically significant. We also tested for the significance of the final course grades (see Table 4). This t-test also shows that the mean difference is not statistically different from zero.

Table 4: T-Test for Significance of Final Course Grades

\begin{tabular}{lrr}
\hline & Clicker Class Scores & Non-clicker class Scores \\
\hline Mean & 340.18825 & 342.3426316 \\
Variance & 2348.713148 & 4352.781776 \\
Observations & 40 & 19 \\
Hypothesized Mean Difference & 0 & \\
df & 28 & \\
t Stat & -0.126989694 & \\
P $(T<=t)$ one-tail & 0.44992807 & \\
t Critical one-tail & 1.701130908 & \\
$\mathrm{P}(\mathrm{T}<=\mathrm{t})$ two-tail & 0.899856139 & \\
$\mathrm{t}$ Critical two-tail & 2.048407115 & \\
\hline
\end{tabular}

Note: The t-test is computed using unequal variances method.

It is important to mention that the range and the variance of the final exam scores are smaller in the treatment group than in the control group (58 versus 61.5 and 260.08 versus 304.58 , respectively). The same can be said for the final course grades measured in points (197.58 versus 233.55 and 2348.71 versus 4352.78 ). These results can be an indication of some positive impact of the use of clickers on student learning by making the final exam scores and the final grades of the "clicker" class closer to the mean compared to the ones for the "non-clicker" class.

A valuable implication of these results is that more sessions and also longer sessions with clickers have the potential to improve student performance. However, the tradeoff between putting more emphasis on clickers' instruction on one hand and the decreased lecturing time on the other hand should be carefully considered, and a good balance needs to be found for the benefits of clickers to outweigh the costs of student instruction based on this technology. A further research in this area is necessary, as well as larger samples of control and comparison groups may provide further evidence in this direction.

\section{Limitations and Recommendations}

No research is without limitations and this technology has also its limitations. Despite these limitations we feel that the advantages of using clickers outweigh the disadvantages. Using clickers does not allow students to ask clarification questions anonymously the same way as they answer the multiple-choice questions. However, it should be noted that there are not many similar systems that can give students the opportunity to ask questions anonymously. For instance, students can use a Google chat (or some other chat room software) where they log in under a different name. That way they can stay anonymous throughout the chat session and can pose different 
questions to the instructor. Another option is to use Twitter but in both cases this requires students to bring laptops or smart phones to class and not many students and also instructors may take advantage of this opportunity.

The qualitative results also pointed to some technical and usability issues. First, a few number of students noted that the clicker receiver was less than optimal and sluggish in responding at times in the Geography class where they had to respond to a question in 30 seconds. Students also indicated that there was little time assigned to answer a question and sometimes the screen was difficult to read due to poor color contrast. This problem with the visibility can be easily solved by providing printed handout with the practice questions which was done in the Microeconomics class.

This research used human subjects, and therefore the Hawthorne effect is an unavoidable bias. The Hawthorne effect suggests that regardless of the experimental manipulation of research subjects, study outcomes seem to improve. One reasonable explanation is that the research subjects are pleased to receive attention from the researchers who express an interest in them (Franke, \& Kaul, 1978). Subjects are always liable to modify behavior when they are aware that they are part of an experiment, and this is extremely difficult to quantify. This means that individuals may change their behavior due to the attention they are receiving from researchers rather than because of the manipulation of independent variables. As researchers, we tried to factor the effect into the research design by applying triangulation method (using both qualitative and quantitative research methods).

Another limitation is that although the use of clickers foster engagement, collaboration, and peer instruction they can be costly as the cost ranges from US \$20-60 per device plus each semester and students need to pay an activation fee (\$15-25). However, this was not a limitation for our research study as clickers were provided free to students to use. As with any other technology, problems associated with clickers can be frustrating and time consuming. It requires more time to prepare questions and set up the technology in class. The use of clickers does require a change in the instructor's mindset from pure lecturing to a much more interactive style of teaching. Faculty planning to use clickers should be prepared to make this change. They should also plan to spend a little time before the course begins to become familiar with the clicker software and hardware. It should be noted that the clicker system is by far the easiest and most user-friendly technology available, but it still needs to be learned. Despite the fact that the findings from this study were not statistically significant in terms of class performance, the survey data and student interviews indicated great benefits from the use of clickers and recommendations for their use in future classes. It should be pointed out that the effectiveness of clickers depends on how the instructor makes use of this technology for instruction, rather than access the clickers themselves. More research is needed to determine if clickers can enhance student learning as compared to the traditional lecture approach. We would encourage instructors planning to use clickers to take advantage of the clicker systems as the reward for the time spent in training will be a smooth-running class in which students take an active part in their education.

\section{Discussion and Conclusion}

Survey results of students who used clickers during review or practice sessions in the abovementioned courses (Principles of Microeconomics and Physical Geography) indicate that this technology increased the degree of their engagement, learning, and motivation. These results were anticipated, largely consistent with research literature discussed above, and encouraging with respect to the use of clickers. The qualitative data analysis of student comments largely supported these findings too. In particular, students referred to an increased level of engagement. It is important to mention, however, that these positive results cannot be attributed simply to the click- 
ers. We should consider the technology in context. In particular, we will evaluate the ways in which the clickers were used, as well as students' views on the factors that made them effective.

Class periods with clicker component began with students completing review questions over the material they had read before class. Students' comments indicated that this served as a powerful motivator not just for attendance, but class preparation as well. Also, students reported that it aided them in understanding what was important in the assigned reading and the degree to which they understood the material. These factors would strongly encourage and engage strategic reading for students, which would likely enhance learning in a particular course. Certainly, quizzes that encourage all of these activities could be given without a clicker system, in a paper and pencil format, but professors would not have real time access to student performance to assist them in modifying the lecture accordingly. Moreover, there are a number of logistical difficulties associated with the paper and pencil quizzes (no immediate feedback), which was something students noted in their comments.

Student responses revealed that the clicker review questions encouraged engagement throughout the lecture period. It is quite possible that students' performance on these questions improved as their engagement and content awareness improved, which would in turn increase motivation. Students were also often allowed to interact with peers before responding to lecture questions. The importance of this type of collaborative interaction, afforded by such a system, is one of the greatest strengths of student response systems or clickers (Judson \& Sawada, 2002). Student comments reflect this fact, with several identifying this as an important factor associated with the use of clickers. High levels of engagement, motivation, and learning were most likely influenced by the presence of this collaboration. Note that other technologies that promote student collaboration, interaction, and engagement (such as Elluminate) will also have a favorable impact on student attention and performance.

Although overall the results were positive, the analyses also identified problematic issues and unanticipated results. With respect to the qualitative analysis, the most striking unexpected finding was the fact that significantly more students disagreed with the statement that "the use of student response system helped me to study more for the course." More students also disagreed or were neutral with the statement that the "use of clickers improved my grade in the course." This seems to demonstrate that the degree to which a student is encouraged to pay attention and engage with the lecture does not necessarily enhance the degree to which the student spends time on content material. These findings may be indicative of the nature of the content and presentation, rather than a statement about the nature of the clickers. Of course, we cannot know to what extent the content influenced this result without examining students' response to different types of content and instructor presentation, so it is simply a speculation until explored further.

In terms of improvement of class performance, even though there was no statistically significant difference in the mean final exam scores and final course grades between the students in the Microeconomics section that used clickers and the section that did not have clickers, we found some evidence that clickers might have helped the treatment group, the "clicker" section, to narrow down the range of scores in this class relative to the control group. We also found that the clicker class had smaller variances in terms of their final exam scores and final course grades. This suggests that the spread of their scores was much closer to the mean compared to the class without clickers. When clickers were used, student learning was better in terms of collaboration and peer engagement than when students had no clicker access. Although the gains in knowledge based on exams and final grades were minimal, clicker use did appear to enhance learning to some extent.

In summary, this research utilized both qualitative and quantitative approaches to assess the effectiveness of clickers in enhancing students learning. The study findings indicated that participants perceived the use of clickers positively in terms of facilitating their active engagement and learn- 
ing in the classroom. Students also reported that clickers were easy and fun to use. There is a growing acceptance of clickers as useful tools for enhancing student learning (see Beatty, 2004). The use of clickers made students more engaged in the presented material compared to the traditional lecture method. When clickers are incorporated into a class they increase active learning, collaborative learning, and student performance. They allow students and instructors to get immediate feedback about the teaching and learning process. The immediate feedback helps students develop confidence as they are able to relate their level of learning and understanding to that of their peers (Perry, VandeKamp, Mercer, \& Nordby, 2002). In some research (for instance, Perry et al., 2002) students have expressed relief when they realized that they were not the only ones struggling to understand the lecture material, thus increasing student confidence levels. Clickers can be used in different academic disciplines and in any class size to help students become critical thinkers. By utilizing clickers, the instructors are able to know more about each of their students' knowledge and understanding about the content material. This enables instructors to make any changes to the instruction process to promote student learning and achievement.

\section{References}

Beatty, I. (2004). Transforming student learning with classroom communication systems. ECAR, 3, 1-13.

Brown, J. S., Collins, A., \& Duguid, P. (1989). Situated cognition and the culture of learning. Educational Researcher, 18, 32-42.

Buhay, D., Best, L., \& McGuire, K. (2010). The effectiveness of library instruction: Do student response systems (clickers) enhance learning? The Canadian Journal of Teaching and Learning 1(1). Retrieved May 23, $2011 \mathrm{from} \mathrm{http://ir.lib.uwo.ca/cjsotl \_ rcacea/vol1/iss1/5/}$

Caldwell, J. E. (2007). Clickers in the large classroom: Current research and best-practice tips. Life Sciences Education, 6(1), 9-20.

Draper, S. W., \& Brown, W. I. (2004). Increasing interactivity in lectures using an electronic voting system. Journal of Computer Assisted Learning, 20, 81-94.

Draper, S. W., Cargill, J., \& Cutts, Q. (2002). Electronically enhanced classroom interaction. Australian Journal of Educational Technology, 18(1), 13-23.

Dolinsky, B. (2001). An active learning approach to teaching statistics. Teaching of Psychology, 28, 55-56.

Driscoll, M. P. (2005). Psychology for learning and instruction. Boston: Pearson Education.

Dufresne, R. J., Gerace, W. J., Leonard, W. J., Mestre, J. P., \& Wenk, L. (1996). Classtalk: A classroom communication system for active learning. Journal of Computing in Higher Education, 7(2), 3-47.

Fies, C., \& Marshall, J. (2006). Classroom response systems: A review of the literature. Journal of Science Education \& Technology, 15(1), 101-109.

Franke, R. H., \& Kaul, J. D. (1978). The Hawthorne experiments: First statistical interpretation. American Sociological Review, 43, 623-643.

Glaser, R. (1990). The reemergence of learning theory within instructional research. American Psychologist, 45(1), 29-39.

Guthrie, R., \& Carlin, A. (2004). Waking the dead: Using interactive technology to engage passive listeners in the classroom. Proceedings of the Tenth Americas Conference on Information Systems, New York, NY, August 2004.

Johnson, J. T. (2005). Creating learner centered classrooms: Use of an audience response system in pediatric dentistry education. Journal of Dental Education, 69(3) 378-381.

Johnson, K., \& Lillis, C. (2010). Clickers in the laboratory: Student thoughts and views. Interdisciplinary Journal of Information, Knowledge, and Management 5, 139-151. Retrieved from http://www.ijikm.org/Volume5/IJIKMv5p139-151Johnson445.pdf 
Jonassen, D. H. (1995). Computers as cognitive tools: Learning with technology and not from technology. Journal of Computing in Higher Education, 6, 40-73.

Judson, E., \& Sawada, D. (2002). Learning from past and present: Electronic response systems in college lecture halls. Journal of Computers in Mathematics and Science Teaching, 21(2), 167-181.

Kyei-Blankson, L. (2009). Enhancing student learning in a graduate research methods and statistics course with clickers. EDUCAUSE Quarterly, 32 (4). Retrieved May 23, 2011 from http://www.educause.edu/EDUCAUSE+Quarterly/EDUCAUSEQuarterlyMagazineVolum/Enhancing $\underline{\text { StudentLearninginaGra/192963 }}$

Laurillard, D. (1993). Rethinking university teaching: A framework for the effective use of educational technology. London, United Kingdom: Routledge.

Lave, J., \& Wenger, E. (1991). Situated learning: Legitimate peripheral participation (learning in doing: social, cognitive and computational perspectives). New York, NY: Cambridge University Press.

MacGeorge, E. L., Homan, S. R., Dunning, J. B., Elmore, D., Bodie, G. D., \& Evans, E. (2007). Student evaluation of audience response technology in large lecture classes. Educational Technology Research and Development, 56,125-145. doi:10.1007/s11423-007-9053-6.

Majerich, D., Stull, J., Varnum, S. \& Ducette, J. P. (2011). Facilitation of formative assessments using clickers in a university physics course. Interdisciplinary Journal of E-Learning and Learning Objects, 7, 11-24. Retrieved from http://www.ijello.org/Volume7/IJELLOv7p011-024Majerich731.pdf

Maletiou-Mavrotheris, M. (2003). Technological tools in the introductory statistics classroom: Effects on student understanding of inferential statistics. International Journal of Computers for Mathematical Learning, 8(3), 265-297.

Maletiou-Mavrotheris, M., Paparistodemou. E., \& Stylianou, D. (2009). Enhancing statistics instruction in elementary schools: Integrating technology in professional development. The Montana Mathematics Enthusiast, 6, 57-58.

Mayer, R. E. (2002). Rote versus meaningful learning. Theory into Practice, 41, $226-232$.

Mazur, E. (1997). Peer instruction: A user's manual. Englewood Cliff, N.J: Prentice Hall.

Morling, B., McAuliffe, M., Cohen, L., \& DiLorenzo, T. (2008). Efficacy of personal response systems ('clickers') in large introductory psychology classes. Teaching of Psychology, 35(1), 45-50.

Pan, W., \& Tang, M. (2004). Examining the effectiveness of innovative instructional methods on reducing statistics anxiety for graduate students in the social sciences. Journal of Instructional Psychology, 31(2), 149-159.

Perry, N., VandeKamp, K., Mercer, L., \& Nordby, C. (2002). Investigating teacher-student interactions that foster self-regulating learning. Educational Psychologist, 37(1), 5-15.

Stagg, A., \& Lane, M. (2010). Using clickers to support information literacy skills development and instruction in first-year business students. Journal of Information Technology Education 9, 197-215. Retrieved from http://www.jite.org/documents/Vol9/JITEv9p197-215Stagg800.pdf

Stowell, J. R., \& Nelson, J. M. (2007). Benefits of electronic audience response systems on student participation, learning, and emotion. Teaching of Psychology, 34(4), 253-258.

Vygotsky, L. S. (1978). Mind in society. Cambridge, MA: MIT Press.

Wit, E. (2003). Who wants to be ... The use of a personal response system in statistics teaching. MSOR Connections, 3(2), 14-20. 


\section{Biographies}

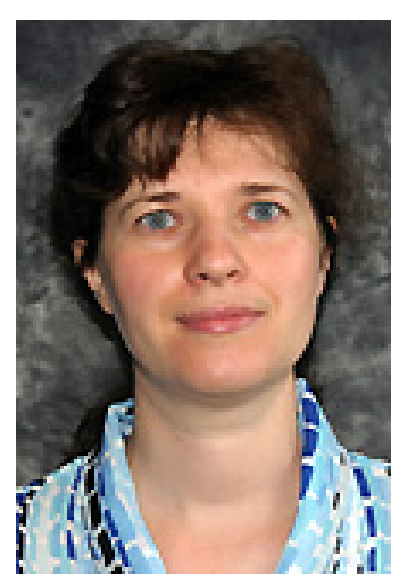

Emma Bojinova is an Assistant Professor in the Department of Economics \& Finance at Canisius College in Buffalo, NY. She received her Ph.D. in Economics from University of Kentucky. Her teaching areas are international trade, microeconomics, macroeconomics, business statistics, and statistics for managers. Her research interests in business education include the use of technologies in classroom instruction and evaluation of online interactive learning platforms. She also conducts research related to industry dynamics, geographic location, and international trade.

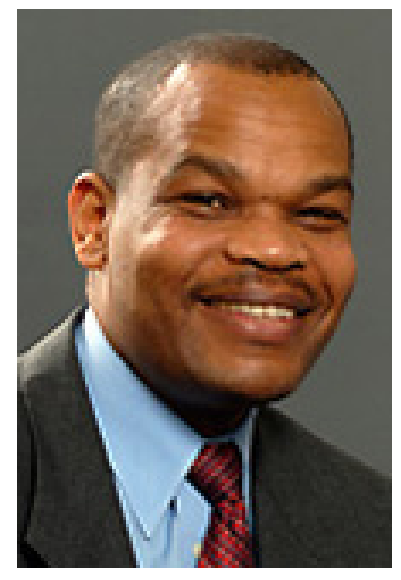

James Oigara is an Assistant Professor in the Department of Education at Canisius College in Buffalo, NY. Dr. Oigara teaches social studies methods courses for pre-service teachers as well as undergraduate physical geography courses. His primary research interests include: integration of emerged and emerging forms of technologies into classroom instruction to enhance student learning. He also has an interest in using geospatial technology like Global Positioning System (GPS) \& Geographic Information Systems (GIS) to teach social studies education. 